\title{
Research on the Performance of the Traditional Culture Art Element in the Plane Design
}

\author{
Keqin Huang \\ Chongqing College of Electronic Engineering, Chongqing 401331,China \\ 1563971762@qq.com
}

Keywords: Traditional culture and art; The plane design; Performance

\begin{abstract}
The emergence and development of graphic design in the world has a common law. They were created as commodity production, along with the science and technology progress, social development and the development. Brought about by the means of transmission of the progress of science and technology innovation, is the development of graphic design plays a huge role in promoting. However, the traditional aesthetics of this national art development also the great influence, the influence of Chinese traditional aesthetics to the Chinese modern plane design should not be underestimated. This article will mainly discuss the traditional cultural art elements in graphic design.
\end{abstract}

\section{Introduction}

As the Chinese modern plane design works, art designers always reveal the subtle influence of traditional aesthetic. Analysis of these effects, certainly some positive factors, will help the development of contemporary graphic design with Chinese characteristics. In the early 20th century, China's modem graphic design in different extent by Britain, the United States, Japan and some countries in eastern Europe, on the basis of the original works of ideological content and artistic quality has improved. And from the late 20th century to now, with the deepening of the reform and opening up, the increasing cultural exchanges, the development of network technology to promote the spread of information. Outstanding graphic design ideas in countries around the world to the modern graphic designers in China provides a good reference and reference. However, life has a rich cultural heritage in China local designers on the earth, in a larger extent inevitably affected by Chinese traditional esthetics thought. From their works we can find that the traditional aesthetic as Chinese contemporary graphic designer offers a wide range of nutrients, to the formation of the establishment of its ideology and work style plays a very important role.

\section{The connotation of the traditional cultural art elements}

Chinese traditional culture contains very rich content, and form is diverse. So, various forms of whether the traditional culture have in common? Or is there some in the cultural elements reflect the basic spirit of Chinese traditional culture?

The first is the "natural" spirit. Every school of thought in ancient China from different aspects to discuss the relationship between man and nature, known as the "nature". It is more obvious in the related theory of Taoism. Such as the daodejing offered to faithfully to know nature, don't add people's subjective imagination, because of the heaven, earth, the universe comes from "tao", and tao is natural, namely the nature of the tao.

The second is the "humanistic spirit". The humanistic spirit of Chinese traditional culture pays great attention to people's moral accomplishment, claims by people of accomplishment and self learning, become a man of noble, have ideal man. Therefore the ancient form of humanistic spirit very the attention etiquette. The "humanities" in the traditional culture spirit not only to the concept of culture, and permeate all aspects of the traditional culture.

And the spirit of "elements". All nationalities in Chinese traditional culture is the domestic people together create, but also absorbed the foreign excellent culture. Chinese excellent traditional 
culture is good at learning the advantages of all kinds of cultural system, and to digestion and absorption, to enrich themselves, the so-called "elements" of the spirit.

\section{The value of the application of traditional cultural art elements in modern plane design}

A national excellent traditional culture is to maintain the lifeblood of a nation, it is not to measure value. China is a multi-ethnic country with a long history, in the vast long national history, the Chinese nation continuously accumulated deep and broad of excellent traditional culture, is our ancestors left us precious cultural treasure. Which most can manifest the culture in graphic design beauty than visual elements in Chinese traditional culture.

An important source of creative graphic design including in traditional Chinese painting, calligraphy, carved code and traditional graphic representation of Chinese traditional culture elements, it has a strong national character, regional characteristics, it exists in the origin and development of national culture, reflect on the people's customs, aesthetic temperament and interest, thus internalized penetrates every generation, accumulation, members of the community of the heart. Today, Chinese traditional culture elements in every aspect of our society has been a lot of attention and application, especially in the field of graphic design to use, such as shadow play, ink to calligraphy, sculpture, all kinds of Chinese traditional culture elements to get a show, and it fully shows that a "wind" in Chinese traditional culture vision is graphic design application present and it has formed the scale.

Chinese traditional culture elements why is favored by more and more, and it itself contains rich Chinese traditional philosophy, aesthetic value is related to such elements as the unique cultural appeal. Inherent in Chinese traditional culture elements of aesthetic value and cultural value, in today's social environment of the commercial smell of companies not only can bring unlimited business opportunities, also can make consumers in for material comforts and obtain more the spirit of the meet.

\section{The application of traditional cultural art elements in graphic design countermeasures}

(1) The traditional Chinese calligraphy in the application of the modern plane design

As is known to all, Chinese calligraphy art has a long history, it is not only a kind of word forms, also is the core of traditional Chinese culture. Historically, people in Chinese traditional calligraphy art has a strong persistent pursuit, with the development of graphic design, traditional calligraphy art has been integrated into the modern plane design. In modern times, the designer through scientific and rational use of traditional Chinese calligraphy art, let design works the breath of progressing with The Times, in many large activities will be able to show in the graphic design. Beijing 2008 Olympic Games emblem "Chinese seal", as the key point is the traditional Chinese calligraphy, seal, writing, calligraphy and so on, and combining the apply to the concept of graphic design, this design not only show the characteristic of the culture in our country, and better able to keep up with The Times steps (as shown in figure 1). 


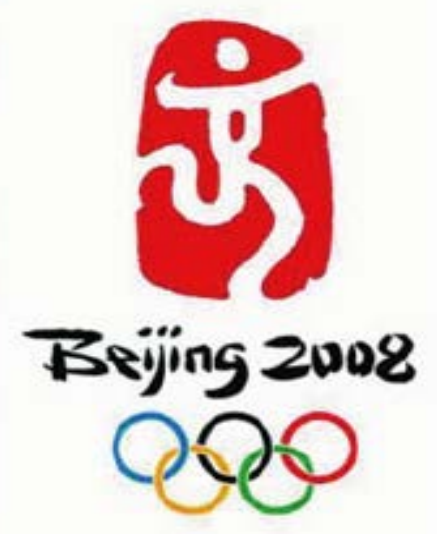

Figure 1 the Beijing 2008 Olympic Games emblem "Chinese seal"

"Chinese seal" logo is to use written form of writing, mainly learn the Chinese characters form powerful national spirit and the humanities culture, the wishes of 1.3 billion Chinese people to the Olympic hopes in the simple a few strokes. Especially the designers to join in the design concept of traditional Chinese calligraphy, the modelling of the character "jing" has carried on the special art processing, make its lifelike, running forward, looked toward victory. Can say, in the modern cultural fusion of traditional calligraphy element in graphic design, can display Chinese characters in a large element of Oriental spirit and national spirit, and symbolically to the unique humanistic spirit of the Chinese nation to promote.

(2) The application of the Chinese traditional patterns in modern plane design

Chinese traditional pattern refers to the auspicious patterns in Chinese folk art, is the masses of working people in their daily production life created by crystal, after long history tradition, extend and perfect its got, become an important part of traditional folk art in China. Traditional Chinese auspicious patterns mainly depend on the form of symbolism and homophonic to mass transfer raise happy, auspicious, reunion, such as moral, such as bats, sika deer and peach contains a "fu, lu, shou" meaning. Will be incorporated in the modern flat design, traditional pattern of its own national characteristics can add rich national characteristics for the design work. Such as Shanghai one hundred - year - old one LaoFengXiang store signs of what is learned our traditional pattern is the appearance of the phoenix, through the special art gimmick to make change, make it has the moral of more plump, said the apprentice moral and a good fortune (figure 2). Through the practice has proved that we apply traditional folk pattern after deformation in modern flat design, not only promoted LaoFengXiang from overall enterprise brand image, will also be able to close the shop and the psychic distance between consumers and brand kindness and sedate sense.

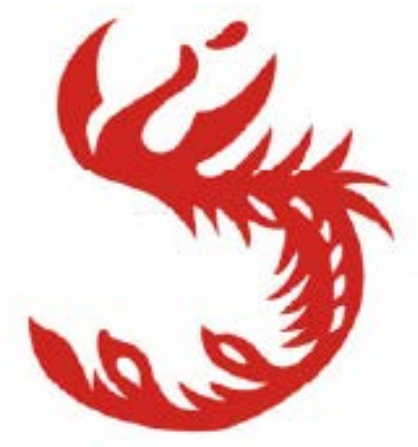

Figure 2 Laofengxiang Store Logo

(3) The application of Chinese traditional colour is designed in a modern flat

Color is by visual sense, with the hand cannot distinguish, within the scope of the audience's visual experience; any color could attract visual pleasure or other complex psychological feelings. Designer knows that the change of environment color on people's lives have a huge role, it can directly affect the audience's visual senses, and adjust the physiological mechanism of nurturing, also affect people's mood, different colour, can make the person produces different psychological 
feeling. In our country traditional color concept, under the influence of theory of Yin and Yang five elements, color system can be divided into as the "five", namely: green, red, black, white, yellow. These five kinds of color are raising their symbolic meaning: black is the work of the baise, in the Chinese history is the longest monochromatic worship time color, symbol sedate solemn, traditional element represents one by one in the present, in our country, is to choose black and white as the main tonal, the unity of Yin and Yang; Symbol is a complex of all colors, white light, is people column color, have a pure wood, easy and comfortable, and make people full of fantasy; Red symbol in ancient and modern design are enthusiastic, bold and unrestrained, auspicious, etc., is the mass-tone attune of the Chinese folk festival; Yellow is a symbol, middle earth, also has a rich and glorious moral: green symbol in China's traditional concept is simple, but in the modern flat design, symbol to raise the vibrant spring, is hope. These five kinds of colour with belong to the visual form of expression, can use the traditional culture, painting and so on many kinds of ways of interaction to condense into national personality color system.

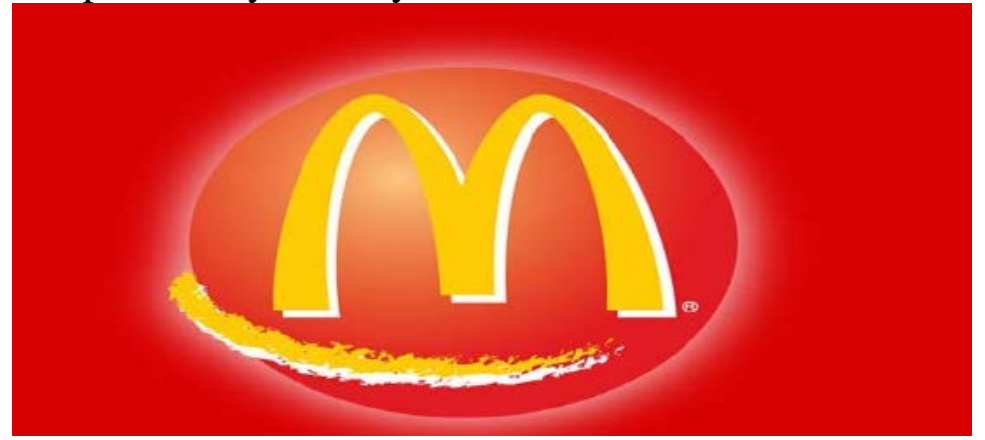

Figure 3 McDonald's

McDonald's (figure 3) is a good example, its advertising propaganda is very concise, not only easy to identify and easy to remember. Images using bold pure yellow color and a lot of red color, gorgeous visible and stimulate consumer's vision. And red and yellow collocation color language, arouse the appetite of consumers, at the same time, in another layer of sense, red and said the positive enterprise culture, energetic upward vitality and enthusiasm. Such collocation, can actively mobilize consumer, at the same time, played a very good enterprise culture using the colour language propaganda effect, can give consumers leave a very profound effect.

\section{Summary}

To sum up, based on the traditional cultural art elements in the design of plane design and the application of text, carries on the analysis and research and summarized. Times in development, social progress, the face of a global diversification of cultural development, excellent designers should have the courage to accept the impact of other national culture. In fully grasp the traditional pattern, the cultural elements at the same time, also want to further study of traditional culture, using modern design methods, the traditional and modern together together reasonably, continuous innovation, advancing with The Times, play to their talents, to design excellent graphic design work. In the current rapid development of society, the traditional pattern and text as a necessary condition in modern graphic design, how the application of traditional culture and art in the graphic design elements, is the modern graphic designers need to attach importance to the problem.

\section{References}

[1] Lloyd D Lindley.A Historical Review of Modern Green Space and Landscaping in America. . 2003

[2] Paula Marincola.What Makes a Great Exhibition?. . 2007

[3] Y.-K. Lim,Keiichi Sato.Describing multiple aspects of use situation: applications of Design Information Framework (DIF)to scenario development. 2006

[4] France Dana,Fu Lei translation.The philosophy of art first. 2009 
[5] David Gauntlett,PENG Lan, etc. translated.Network Research --- the digital age media studies reorientation of. 2004

[6] Richard Hickman.Research in Art and Design Education: Issues and Exemplars. 2008 